\title{
Familiar aliens: 'Teletubbies' and postmodern childhood
}

Article

Accepted Version

Bignell, J. (2005) Familiar aliens: 'Teletubbies' and postmodern childhood. Screen, 46 (3). pp. 373-388. ISSN 1460-2474 doi: https://doi.org/10.1093/screen/46.3.373 Available at https://centaur.reading.ac.uk/23199/

It is advisable to refer to the publisher's version if you intend to cite from the work. See Guidance on citing.

To link to this article DOI: http://dx.doi.org/10.1093/screen/46.3.373

Publisher: Oxford University Press

All outputs in CentAUR are protected by Intellectual Property Rights law, including copyright law. Copyright and IPR is retained by the creators or other copyright holders. Terms and conditions for use of this material are defined in the End User Agreement.

\section{www.reading.ac.uk/centaur}

\section{CentAUR}

Central Archive at the University of Reading

Reading's research outputs online 


\section{Familiar Aliens: Teletubbies and Postmodern Childhood}

Jonathan Bignell

This article argues that the British pre-school children's television programme Teletubbies develops some of the theoretical concerns of postmodernist criticism. The aim of the article is to consider how this theoretical discourse and Teletubbies work together to rethink the notion of the child, as a conceptual category and an audience category imagined for British television. I shall argue that the aesthetic of Teletubbies corresponds to the reflexive textuality identified by postmodernist theory, and instantiates some of the confusions between self and other, adult and child, that this theoretical discourse has debated. ${ }^{1}$ Some of the existing work on Teletubbies discusses it in terms of its effects on the child audience and its relationship to educational and social goals, using arguments that adduce what is claimed to be knowledge about actual children. ${ }^{2}$ In contrast, this article discusses arguments that derive from abstract conceptions of childhood as a condition or life-stage. However, I demonstrate here that these two approaches keep merging into each other, and that this issue is part of the greater problem of boundaries, propriety and ambivalence that postmodernist thinking has addressed and of which it is a symptom. The French theorist Jean-François Lyotard is interested in childhood as a discursive category, rather than in actual children as concrete individual subjects. He discusses childhood in relation to notions of process, such as the process of constitution of the subject, and the relation between a subject and an object, event, or experience. Discussing childhood opens up the issue of teleology, for the concept of the child is understood as that being who will become an adult, and the concept of adulthood is produced against the retrospective invocation of the concept of the child. Similarly, for Lyotard, a text is 'modern 
only if it is first postmodern'. ${ }^{3}$ A completed state (of adulthood, or modernity) is constituted by a moment of formation (childhood, or the postmodern) which is retrospectively constructed. This works rhetorically to establish childhood as a subversive model of subjectivity, or of new configurations of textuality and politics. Childhood is represented as a way of being in which cultural formation is still in process, so that childhood is part of culture and also borders it, anticipates it or transcends it because it is not yet fully integrated into it.

In what follows, these questions are taken further with a predominant focus on Teletubbies rather than the theoretical context that I have briefly outlined. I return later to theoretical discussion around Lyotard's influential philosophical and critical writing about postmodernism, and consider the aesthetics and production contexts of Teletubbies in terms of the problems around television and childhood that the programme raises. My main argument is that Teletubbies casts childhood as both familiar and alien, just as the Teletubbies themselves are, and poses television as a mediator of the uncertain boundaries between adulthood and childhood, familiar and alien, human and inhuman. In doing this, Teletubbies participates in a contemporary structure of feeling whereby these dualities are being questioned and rethought in media culture as well as in postmodernist theoretical discourse. Because television is a key boundary space that negotiates understandings of adulthood and childhood, self and other, now and then, here and there, it is both an instance of that structure of feeling and a means for worrying over and modelling it.

Teletubbies was made by Ragdoll Productions for BBC, in 260 episodes of 30 minutes each. It was first screened in Britain from 1997-2001, followed by sales to over 120 countries and translation into over 40 languages. The series was shot at a large outdoor set near Ragdoll's headquarters in Stratford-Upon-Avon. The set consists of a sculpted landscape of 
hillocks populated with flowers and large rabbits, with the Teletubbies' home, the Tubbytronic Superdome, at its centre. ${ }^{4}$ The Teletubbies are four pot-bellied creatures with short limbs, large heads and coloured furry skin, who are played by actors in body-suits. Tinky Winky is purple, Dipsy is green, Laa-Laa is yellow, and Po is red. Each Teletubby has a distinctive appearance, marked not only by colour but also by the individuating aerial-like structures on the tops of their heads and by their personal possessions, like Tinky Winky's handbag or Dipsy's hat. On the edge of Teletubbyland stands a tall metal windmill, which periodically begins to turn and broadcasts short sequences of actuality film showing children playing together, for example running on the beach, splashing in puddles or baking cakes. These sequences are beamed onto the stomach of one of the Teletubbies, who each has a silvery patch there in the shape of a television screen. The Teletubbies look forward to these broadcasts and react to them with pleasure, demanding once they finish that they be played 'Again, again', as they usually are in a slightly truncated form. Aside from this, the Teletubbies gambol in their pastoral surroundings, play with objects, dance, sing, and take their meals of TubbyToast and TubbyCustard inside the technological space of the Tubbytronic Superdome where Noo-Noo, their robotic cleaning machine, sweeps up after them. At intervals, props appear in Teletubbyland for them to encounter, animated clouds, rain or creatures appear, and lengthy animated sequences bring, for example, three ocean liners sailing into Teletubbyland on a miraculous flood, or animals walking two-by-two across the landscape. Much of the visual content of each episode is accompanied by music, the Teletubbies' own infant language and laughter, and adult voices represented by voice-over narration and the words of the Voice Trumpets, large telephone receiver-like objects that emerge from the ground to give instructions or make suggestions. In the sky above Teletubbyland, an animated sun with the 
head of a baby within it looks down on their antics, responding with amused gurgles, laughter or surprise.

\section{Teletubbies and television aesthetics}

The reflexivity and intertexuality of Teletubbies are its most notable textual features, and there are numerous references to broadcasting, communication and storytelling. Each episode begins with a voice-over narration (by Toyah Wilcox) announcing 'Over the hills and far away, Teletubbies come to play', referencing the discourse of nursery rhymes. The Teletubbies are aware that they are being watched by their viewers, and greet their audience at the beginning of each programme and wave goodbye at the end. Each episode hollows out a space for its audience to interact, for example by joining in the dances and songs that each programme includes, when the camera is positioned to view the Teletubbies in long shot performing in a tableau. Similar long takes, usually in long shot, are used to present the animated figures and objects that suddenly appear in Teletubbyland, for example when after a sudden downpour from animated clouds, a large silvery lake appears and three ocean liners move across it to music based on the Christmas carol 'I Saw Three Ships Come Sailing In'. The large liners move slowly and majestically across the lake while the camera remains static, producing an otherworldly and mesmerising effect that is also present in similar long animated sequences in other episodes. Teletubbies draws its narrative ideas from outside television, from nursery rhymes, children's songs or fairytales, for instance. But the visual aesthetic of the programme insists on the capacity of television to bring actuality, performance and computer animation together into a coherent textual world that dissolves the boundaries 
between these representational forms, and between television and the material that it reworks. Television scholarship has defined the medium as one in which a distracted domestic viewer glances at primarily realist and simple image compositions with low density of visual information, where sound predominates over image. ${ }^{5}$ But Teletubbies (like television science fiction of which it could be seen as a variant) can both use and surpass this. Animations of nursery rhyme animals and the story of Noah's ark in Teletubbies, for example, draw on traditional narratives but foreground post-produced spectacular effects and the visual aesthetics of digital morphing and movement. The programme's aesthetic dissolves distinctions between the alien and familiar by creating an interplay of new simulation technology with traditional content from television and outside it, and with live action. The frequent repetition of fantastical sights and events, and the effect of music and voice-over to reassure, make Telebubbies a programme where anything strange might happen, but within a restricted set of codes where some of what happens is familiar and where some of what may be alien is familiarised. On the other hand, factors such as the science fictional alienness of the Teletubbies and their environment, and the transposition of traditional rhymes and stories into loosely structured narratives centring on repetition and visual spectacle, displace familiar elements from the conventional forms that might otherwise tame them.

There is an assumption in Teletubbies that television comes from somewhere else, and is supervised by the giant windmill and other authorities such as the programme's adult narrators and the instructions of the Voice Trumpets. But inasmuch as the Teletubbies are childlike and take pleasure in television by viewing the actuality sequences on their stomachs, and perform for the camera in their dances and repeated 
actions, the episodes are emphatically structured to invite the audience to take up a viewing position that aligns the viewer with them 'inside' television. Television becomes both alien and familiar itself, both a show coming into the home from elsewhere, and an interactive experience that spills out of the television set and happens in the viewer's space. The relationship between the Teletubbies and the adult narrators, Voice Trumpets and the windmill is similar to the inherited conventions of British children's television, in that the Voice Trumpets' male voice tells them to go to bed at the end of each episode, and has an authoritative adult knowledge of the actions of the Teletubbies so that it can function as a knowing 'voice of God' narration. This matches the control exercised by adults over the children and childlike characters in most children's programming. ${ }^{6}$ On the other hand, the adult narrators do not have full control of the Teletubbies. A voiceover tells them to go to bed at the end of each episode, but they always resist, repeatedly voicing a wheedling 'No' and hiding behind the set's grassy hummocks. The Teletubbies have a limited but real ability to resist adulthood's control and its supervision of their actions. Television and adulthood, therefore, are represented as a means of apprehending such 'real-world' concerns as the constraints of time and authority, or the spatial and causal relations that govern action and nature. But television and childhood are also a welcome gift to the Teletubbies and to the programme's imagined audience, and an opportunity for pleasure and wonderment that adulthood does not wholly control. This productive tension between play as an activity for its own sake and the organisation of activity for a purpose continues at the level of episode structure. In one episode, for example, sequences are loosely held together by the theme of water, leading to a game of jumping in a puddle in Teletubbyland, the arrival of the ocean liners mentioned above, 
and an actuality sequence showing nursery school children playing in the rain. Narrative form provides some thematic coherence to episodes, but individual sequences play with and develop thematic components at length and independently. Play and distraction in Teletubbies link the Teletubbies' actions, the actions of children in the actuality sequences, and also the text's play with the real and the imaginary. But furthermore, television's divisions into time-bounded programmes is disrupted by the Teletubbies' refusal to go to bed and let the programme end, and internal linearity is countered by the repetition and apparent randomness of the happenings in Teletubbyland. Overall, Teletubbies works on disrupting distinctions between the actual and the virtual, the televisual and the extra-televisual, and the boundedness of narrative and authority versus resistance to or negotiation with those constraints. In these ways, the identity of television itself as either 'from out there' or 'in here' for its viewer is confused, and television textuality oscillates between structure and play, constraint and excess.

When the giant windmill beams documentary segments featuring children in the 'real world' beyond Teletubbyland onto the Teletubbies' bellies for them and the audience to see, the Teletubbies and the audience are aligned with each other in witnessing these segments. The Teletubbies stand waiting for the images to appear, chortling and cooing, until one Teletubby is selected and the first live action frame appears on his or her stomach. At this moment, the camera closes in on the Teletubby's belly, accomplishing a transition into the actuality footage so that it fills the screen. Putting the actuality image onto the bellies of the Teletubbies is in one sense a pragmatic decision on the part of Ragdoll, because the programme's producers decided it was boring to represent television by including the television set as an object within the 
fictional world. In Ragdoll's earlier series Rosie and Jim (Central for ITV, 1990-2), the canal boat in which the eponymous puppet characters and their human companions live has a television set among the domestic furnishings of the boat, and although the television set shows material that the characters can interact with, it remains a relay device that is not easily integrated into the main action. By contrast, putting television images on the Teletubbies' stomachs means that television and its possibilities of relay are embedded literally on or in the characters. The television screen becomes part of the Teletubbies' skin, so it exists at the border between self and other, inside and out, body and environment. The fabric skin of the Teletubbies becomes a boundary that both encloses their bodies and opens them into another world, mediating notions of subjectivity, identity and perception by confusing the distinctions between inner and outer, and between the this-here of Teletubbyland and the there-then of a 'real' world of children. Their bellies are windows and screens, bodily and material but also spaces of virtual projection, 'in' Teletubbyland but linking it with the 'real world', and thus they pose the viewer's television screen as a boundary surface that is both 'here' for its viewer and opens onto a multiple 'there' of possibility.

Each day in Teletubbyland begins as the sun baby rises swiftly into the sky, and the end of the day is marked by the setting of this sun. By marking time, the sun seems to supervise Teletubbyland, suggesting the baby's diegetic agency and by extension the supervision of the programme by a notion of childhood and the incorporation of an empowered figure representing it. But on the other hand, the sun baby has no direct agency over anything that happens. It looks down amusedly at the Teletubbies and is spatially separate from the action of the main characters, paralleling the imagined child 
viewer who has no direct control of the programme since it is made by adults from the technological and institutional world of television. Television is established as an opportunity for wonderment and joining in, thus familiarising television but attributing its pleasures and its control ambiguously to its imagined author-figures and to a range of delegates inside the diegetic world who represent the audience. In many ways and at various levels of meaning, Teletubbies reflects on its own televisuality and the notions of medium, communication, institutional authority and the possibilities of play with meaning in television.

\section{Childhood for television}

Thus far I have been discussing childhood as a way of being that is represented by the Teletubbies' childlikeness and that is shaped by the programme text's modes of address to an imagined audience. I have not taken account of what this may have do with actual children. However, Ragdoll Productions spends considerable time and effort on empirical research prior to the design and production of programmes, and this raises and perpetuates a common problem of knowledge in relation to actual children and their function as instances of the concept of childhood. ${ }^{7}$ Focus groups of children are interviewed at Ragdoll's headquarters, hours of video recordings of children playing and interacting with television programmes are gathered there since the company buildings are also a popular visitor attraction for families, and the extensive opportunities built into the design of Teletubbies for active play and interaction with the programme allow for the multiple and often physical kind of response to television which such research reveals. For Ragdoll, setting up play environments to be videoed is a way of finding out what children 'naturally' do, producing useful knowledge to help make its 
programmes. This positions the actual child as an originary object of knowledge, that is already true to itself and can be learned from by adults in order to construct a concept of the child audience and its needs or competencies. However, the notion of actual children as natural, having natural behaviours that can be observed, relies on the assumption that childhood is already there in actual children, untouched and available to be known. So the natural being of actual children can only be natural inasmuch as the concept of a natural childhood is placed at an origin that is other to the processes and acquisition of knowledge. It seems that that which is to be known exists outside knowledge and is brought into it, but the bringing of natural childhood into knowledge already requires that natural childhood to have been set up as its other and its object. Once the supposed natural childhood is claimed as an object of knowledge then it is no longer natural in that originary and alien sense, since the concept of natural childhood is defined precisely by its quality as an alien unknown. Ragdoll creates the possibility of knowledge of childhood so that it can be mobilised as knowledge and then relayed back to actual children in the form of programmes aimed at a child audience which is also necessarily a concept rather than an actuality. There is a circle of knowledge production, in which Ragdoll creates an image of childhood from actual children so that other actual children can be imagined as an audience. Ragdoll also creates a concept of the child existing in a natural state before that knowledge about actual children, whose behaviour might confirm or modify it. The concept of childhood and the activity of actual children seem to legitimate each other, but are instead two different signifieds whose roles as antecedent or subsequent can be reversed.

Some of these problematic boundaries are also evident in the programme makers' initial conception of the programme's central characters as childlike adults. Teletubbies' co-creator 
Andrew Davenport imagined the Teletubbies through an analogy between toddlers and astronauts. ${ }^{8}$ The original programme idea was based on two astronauts in space-suits who inhabit an English garden, but who are miniature in size and dwarfed by the plants and garden furniture around them. The familiar garden environment would become an alien place for exploration, and the clumsy-suited astronauts would work cooperatively to cope with its challenges. Subsequently, in collaboration with the head of Ragdoll, Anne Wood, Davenport developed this idea into the four clumsy Teletubby aliens in the rolling landscape of Teletubbyland. The Teletubbies' appearance is human, both in the parallel between toddlers' body shape and the Teletubbies' relatively large heads, short limbs and pear-shaped torsos, but also alludes to the clumsiness of human astronauts in space-suits falling over and losing dexterity when wearing the suits in low gravity. So the Teletubbies are both childlike and also like adults reduced to childlikeness by an alien environment. The function of the parallel with astronauts is to render the Teletubbies' pastoral and familiar landscape alien, as a resource for them to explore as if it were an alien place. Clearly this derives from the programme makers' conception of childhood as characterised by discovery and a relation to the world that includes the negotiation of self through encounters with other objects and people. It also draws the adult and technological enterprise of space exploration into an analogy with the physical, sensory and cognitive underdevelopment attributed to childhood, so that what Apollo 11 astronaut Neil Armstrong described as a 'small step for Man' in this adult activity is literalised as the small and tentative steps of a toddler. The parallels with astronauts and toddlers familiarise the Teletubbies' appearance and physical movement, but the Teletubbies are also in some ways uncannily monstrous and inhuman. The programme draws on science fiction's popular forms for imagining aliens, by representing them as coloured, naked alien colonists who have aerials 
on their heads and understand Earth from the television pictures they have intercepted. ${ }^{9}$

Teletubbies also provides opportunities for specifically visual revelation of alien and intriguing creatures, objects and landscapes as I have discussed above. Again, the apparent stability of contrary terms is disrupted by the Teletubbies' derivation from ideas about human-like aliens and alien-like humans, where childhood is the terrain on which these are brought together and become equivalent.

Lyotard's work on the boundaries between human and alien, and how what is human is defined by but also contaminated by the inhuman, make a similar argument to my own above, and further problematise Teletubbies' associations and distinctions between childhood, adulthood and media technology. In The Inhuman, Lyotard discusses the conception of the child as a figure for the component of the inhuman within the concept of the human, as Dan Fleming has also noted. ${ }^{10}$ Lyotard's analysis refers to the child as a concept and not an empirical entity, and argues that it is inhuman because childhood presupposes that a process of development, and the ideologies which shape the meaning of childhood in Western culture, have not yet finished processing it into the normative human state that adulthood is understood to be. Lyotard also argues that postmodern technoculture is inhuman in the sense that it is an inorganic and external supplement to the human body and subjectivity that entangles itself with and penetrates the human body and psyche. There are theorists, such as Neil Postman for example, who have argued that contemporary technological media culture puts an end to the natural innocence of childhood. ${ }^{11}$ So one way of understanding the postmodernist assertion that the subjects of highly developed Western societies are living at the end of history and at the end of the human is to think of these endings as the end of the child, since the child is conceived as the origin of the human. But following Lyotard's argument that connects 
childhood to the postmodern and to media technoculture would produce the opposite conclusion. For Lyotard, childhood as origin of the human is inhuman itself, because childhood is defined as that condition which has not yet become the rational subjectivity of adulthood that characterises humanity in modernity. So childhood, the postmodern, and technoculture are analogous to each other as supplements that challenge the borders of the human. Postman invokes childhood as an other condition that is the object of contemporary consumer culture's deformation of the concept of the human, and argues that commodification's negative effects can be shown by the damage it does to childhood. By contrast, Lyotard invokes childhood to assimilate it with postmodernism, and to argue that adulthood's technoculture produces an agency for adulthood that matches the playful and positive agency he finds in childhood's state of becoming. These two approaches each deal with the stakes of modernity and media culture, with opposite conclusions, but each adopts childhood as the conceptual terrain for describing how subjectivity is transformed and made other to its accustomed forms. The discursive construct of childhood can be deployed theoretically to deconstruct the notion of the subject in modernity, and can be connected to the technological media culture which similarly borders and challenges human subjectivity. The textuality of Teletubbies, through its ambivalent invocation of conceptions of childhood and of television, is engaged in this struggle over the borders between human and inhuman, and the questions of aesthetics and politics that the struggle raises.

Corresponding issues are raised by the series' relationship with commodity culture, since Teletubbies shares with other television progammes the conception of childhood as a market category that, while protected by legislation and guidelines of various kinds, is not essentially different from the consumer culture of adulthood. The sale of licensed products 
associated with Teletubbies, like toys, videotapes, clothing and foods, raised $£ 330$ million in its first two years, raising and maintaining the programme's profile, and supporting the BBC's brand as a public service broadcaster. The Teletubbies' simultaneous familiarity and alienness was extended by their penetration into the material environment of the home and family, where the commodification represented by Teletubby dolls, for example, could be understood in Postman's terms as the colonisation of 'natural' childhood and its homely setting by inhuman things. On the other hand, Teletubby dolls are things that provide ways of thinking about the self as a thing that takes the form of an alien other for another human being. The dolls pose an equivalence between being a Teletubby and being a child, in their physical form and in the identifications with them that play makes possible. ${ }^{12}$ If human subjects use things like toys to define their selves in distinction to those things, the subject can also be thought of as a thing against which another subject could define himself or herself. The self is constituted against what is alien and other to it, but thus comes to occupy the role of an other thing for another subject. Teletubbies merchandise is no different to merchandise from other programmes in this sense, so there is no need to develop this argument in detail here. But my earlier points about how the Teletubbies are both human and inhuman, childlike and alien creatures, are given added support by the inherent duality in these respects of the toys representing them. Because the Teletubbies are familiar in the sense they represent childhood and are childlike, they make childhood familiar. Yet because they are alien, non-human creatures, they make childhood alien too when they represent it. Teletubby dolls and other toys both belong to childhood and mark its difference from adulthood, and as commodities they also draw childhood into sets of relationships with objects and meanings that are familiar aspects of adult consumer culture. The dual significance of the Teletubbies as both familiar and alien adds an interesting twist to 
this argument about the commodity culture of toys, by drawing attention to the ways in which toys in general are consumer objects that blur the boundaries between childhood and adulthood, introducing the notions of getting and having objects into childhood, and the notion of becoming a self by playing out identities in parallel and in contrast to objects into adulthood. Toys are often blamed for making childhood as acquisitive as adulthood, but far from toys determining what the culture of childhood is, the production of the embodied human self in childhood works by establishing an inhuman and alien object (the toy) in order to distinguish it from the human and familiar entity that it will help to define as its other (the child). ${ }^{13}$ The same process shapes the way that the concept of childhood is invoked as the determinant of adulthood, where childhood is projected retrospectively as an other epoch in which adulthood was already being prepared for but whose meaning can only be understood subsequently. But as I argued above in relation to the deployment of the concept of childhood in Lyotard's writing, this leaves the concepts of the toy and of the child as inhuman, both coming before adult subjective agency, and also inhabiting it as the sign of its own possibility. The concepts of childhood and the toy occupy the same discursive position as the postmodern does in Lyotard's formulation, because each of them is projected backwards as a foundation for what happens later. For Lyotard, the postmodern is that which is not yet determined, but which will have been the founding moment when a subsequent state of modernity is formed. The same logic produces Lyotard's conception of childhood as a state of becoming whose meaning and identity can only be understood retrospectively.

The aesthetic forms of Teletubbies match dominant conceptions of what television for children should do to develop competencies that will be needed in adulthood, and thus create a concept of childhood that legitimates some kinds of television aesthetic and 
excludes others. There is a childhood constructed for television, which legitimates television for children. Roger Singleton-Turner, for example, an experienced BBC producer and director, has written a book addressed both to programme-makers and also a wider audience of educators, parents, and officials concerned with children and television. ${ }^{14}$ His work argues that children and adults have different competencies and knowledge, and he sets up a conception of childhood based on discourses of knowledge from developmental psychology and from theories of media literacy. For example: 'The whole grammar of television needs to be learnt by each viewer. There is evidence that the language of film and television is learnt in a similar way to spoken language and that children of increasing maturity accept with understanding an increasing vocabulary of filmic conventions. ${ }^{15}$ The consequence of this for the form of programmes for children is, he argues, that narrative forms should be relatively linear and clear, to avoid a child viewer creating 'extraordinary constructions in his [sic] mind to explain what he has seen'. ${ }^{16}$ A discursive model of child development is constructed as an evolutionary learning process which moves teleologically towards the normative adult viewer. The specific results of this developmental schema are to proscribe the audio-visual form of programmes, according to the 'stage' in development which the child is assumed to be at, with the simplest forms for the youngest audience. In programmes for the youngest audience, like Teletubbies, relationships between long shots and close ups should be signposted, to avoid confusion over the sizes of objects and people. Time ellipses between shots should be rare in programmes for young children, and cutting rates should be slower than for an adult audience. Thus the form of children's programmes that Singleton-Turner recommends comes to resemble early cinema, and children's 
programmes repeat the 'evolution' of film from a static camera shooting theatrical boxed sets, with little cutting or change of frame size, to a contemporary style of rapid montage, fast cutting, and unmotivated use of pan or close up in programmes for older children. The learning curve of child viewers becomes a condensed version of the normative and teleological history of audio-visual communication.

These principles for making programmes aimed at young children repeat the problems of knowledge that I outlined in relation to Ragdoll's research into actual children's play. They propose that childhood is characterised by underdevelopment of the faculties of cognition that make sense of dimension, cause and effect, temporal sequence and spatial relationships. Research into actual children's behaviour legitimates this, establishing childhood as an other mode of being to adulthood, and leading to specific television forms that aim to give back to the imagined child audience the kind of television that the research has claimed it needs. Ragdoll's Teletubbies webpage briefly explains the form of the programme in these terms, for example: 'In Teletubbyland, things happen again and again, giving a child time to discover patterns of cause and effect, allowing a child to anticipate what will happen next. ${ }^{17}$ Repetition of this kind can be seen when the actuality sequences of children playing are repeated, when individual Teletubbies repeatedly perform an action, such as jumping into a puddle, and in the repetition of narrative segments that persist from episode to episode, such as the opening line of voice-over narration, the Teletubbies' welcoming waves to the camera, or their refusals to go to bed at the end. Spatial relationships and the proportionality of objects of different sizes are built into the design of the outdoor set, where the hillocks of the landscape allow for Teletubbies to walk towards a static camera from a distance, 
periodically disappearing behind hillocks and reappearing again, or wending their way towards the camera from afar along the contours of the landscape. However, the programme also plays with this carefully structured environment of time and space, for example in an extended sequence where Tinky Winky 'impossibly' puts all kinds of objects discovered in Teletubbyland into his bag. Objects both large and small are stuffed into the bag, which is clearly much too small to contain them all. This is a magical game with proportional size that can only achieve its comic effect in distinction to the rules of space and proportion that the programme has already worked to establish. As in other aspects of my argument here, Teletubbies establishes rules so that it can break them, or makes ideas familiar so that they can become alien, and plays with distinctions and oppositions so that they are deconstructed.

Teletubbies is thus addressed to an imagined audience defined by its childhood, and the kinds of cognitive competence that this conception presupposes. But the programme includes ideas and aesthetic forms that are alien to this, and integrates them as familiar kinds of trope, thus destabilising what alien and familiar mean to the series. Similar reversals and ambiguities affect the way that the programme's address to its viewer is described. The Ragdoll webpage explains: 'Teletubbies is a responsible, enjoyable half-hour where our youngest viewers find their place: a playful, imaginative world inhabited by gentle, loving characters exploring and experiencing everything around them. The series is also a wonderful opportunity for parents to share the joy of first discovery through children's eyes.' Teletubbies is offered to adults as a site where children 'find their place', both within the television schedule and as a fictional world where the concept of childhood is represented in concrete audio-visual forms that characterise it as 'imaginative' and 'playful'. The Teletubbies represent childhood inasmuch as 
they are 'gentle' and 'loving' beings whose predominant activities are 'exploring' and 'experiencing'. Thus the programme's imagined audience are posed as equivalent to the Teletubbies. Furthermore, adults are given the opportunity to 'share the joy of first discovery' by viewing from the audience position laid out for children. It is suggested that the adult audience can partake in this experience of childhood and remove the apparent boundary that separates their experience from the childhood which the Teletubbies and the child audience are said to already have, and which adulthood has supposedly lost. Adulthood can regain an equivalence with childhood, the text claims, through the watching of Teletubbies. So there is a series of displacements here in which Teletubbyland, childhood and adulthood become equivalent to each other. And further, since each of these identities become the same, the difference between them is erased. Teletubbies becomes a ground on which boundaries and distinctions become confused and blur into each other, following the logic of dissolution that I have been identifying in different contexts throughout this article.

Teletubbies works with ambivalent and contradictory conceptions of what childhood is and means for Western thought, and for British children's television in particular. Childhood is defined negatively and retrospectively against adulthood, thus raising the issues of how identities are discriminated and represented, and how the one turns into the other. Television for children is made by adults, so determining what childhood is requires a complex and conflicting range of understandings which seek to shape childhood and mobilise it discursively. The contradictory place of childhood in Western culture exists at an uncertain border between human and inhuman, self and other. On the one hand, childhood has been seen (in the Christian tradition) as a predisposition to immorality and sin, as irrational and incomplete. On the other hand, Romantic conceptions of childhood pose it as uncorrupted, innocent, authentic, and in 
contrast to the guile and artifice of adulthood. This Romantic childhood is a sign of loss and nostalgia, regarded as a potential and an origin that is always already lost, and thus desired. It is this duality in conceptions of childhood as inhuman and improper, or as central to the proper essence of the human, that produced the debates about the value of Teletubbies.

Some commentators argued that Teletubbies was not educative enough, because it uses some 'primitive babytalk' like 'Eh-oh' for Hello, and does little to encourage understanding of reading, number or spatial concepts, for example. ${ }^{18}$ The demand for television to communicate knowledge and citizenship rests on the argument that the function of television for children is to lead them towards adult capabilities and discipline them in the norms of adulthood. By contrast, the merchandising effort around Teletubbies and other children's programmes can be seen as a cynical ploy to make money and as evidence of television's contamination of childhood by the ideologically suspect world of adulthood's commodities, brands and consumerism. This critique rests on the value given to childhood's supposed freedom from the acquisitiveness and commercialism of adult culture, where childhood is regarded as a privileged realm of 'natural' play and freedom that should be protected. The relative lack of paternalistic instructional discourse in Teletubbies, the child-centredness that might be found in the supervisory gaze of the sun baby who floats above Teletubbyland, and the Teletubbies' childlike love of falling over, hugging and splashing in puddles, for instance, derive from its producers' liberal embrace of the latter of these conceptions of childhood. Anne Wood was quoted to that effect in a Radio Times feature in 1997: 'We knew there would be debate about whether it is possible for children to make their own meaning or whether they constantly need instruction from an adult. There are people who still believe the only way to help children is to instruct them. We're coming from a different philosophy. We credit our viewers with lots of 
imagination. ${ }^{19}$ The debates about whether Teletubbies promotes the acquisition of language and social relationships, or wallows in directionless play, rehearse old arguments about the aims, legitimacy and value of children's television in an era of waning certainty about the function and value of public service television. ${ }^{20}$ Parents, educators and regulators targeted the $\mathrm{BBC}$ in particular to urge that programmes for children should have greater regard for the functions of television in education and child development. These responsibilities on the part of programme-makers and broadcasters have underlain much of the discourse of British television production for children in the public service tradition, since PSB has aimed to provide educative or improving programmes, and to offer a range of different programme types at different levels of accessibility for adult and child audiences. The issue is whether television, made by adults for children, should discipline an unformed and wayward childhood out of its alienness and towards adulthood, or whether television should cradle an Edenic and natural childhood whose difference from adulthood is a sign that it is the essential core of humanity before adult culture deforms it.

\section{Why choose Teletubbies?}

There are two related but contrary ways of thinking about the relationship between childhood as a concept and actual children, and in both everyday and critical discourses these tend to blur and turn into each other. This problem has affected very many discourses from moral panics in the popular press, educational legislation, television policy and of course the behaviour of both adults and children. I have suggested when mentioning Ragdoll's research above that actual children might be observed in order to elucidate what characterises childhood. This would produce a concept of childhood that could be mapped back onto actual children, and would 
facilitate evaluative judgements about what belongs to childhood and what is alien to it. On the other hand, childhood can be conceived as a self-sufficient concept that transcends what actual children do, and could be employed as regulatory idea that would legislate for how children should behave, how adults should relate to children, and how television should be made for them, for example. In writing about childhood and children, there is a perpetual oscillation between using the concept of childhood as an explanatory frame for understanding actual children, and adducing actual children's actions to support or challenge conceptions of childhood. The two issues here are which comes first, the concept or the 'evidence', and how the boundaries around childhood set up its propriety by including some elements in it and excluding others in a way which facilitates the eruption of what seems alien into both childhood and its other.

Teletubbies is a fascinating site for analysing negotiations around conceptions of childhood, the audience imagined for children's television, and representations of human and alien, adult or child subjectivity. Childhood for Telebubbies is familiar but alien, so is adulthood and so is television. The fact that childhood is both an anterior prefiguration of adulthood and an other to it, means that the Teletubbies and childhood represent, at the same time, boundaries, others, prefigurations, and confusions of categories. Television enacts and mediates the categories of adulthood and childhood, alien and familiar, and is represented as both familiar and alien itself, so it is part of these debates as well as a medium for working them through. The analysis of Teletubbies is therefore a productive way of addressing questions of identity and representation, but the programme is a privileged example because of its reflexive work on questions of what television can be and what it can do. It for these reasons that the programme appears as one of fifty 'key' television progammes in Glen 
Creeber's recent collection and as a case study in Karen Lury's recent book. ${ }^{21}$ These evaluations and analyses by other writers have argued, as this article does more implicitly perhaps, that Teletubbies is complex, revealing and enjoyable. It is not just a programme that lends itself to the instrumental application of postmodernist theoretical arguments, and I have tried to avoid addressing it in that way here. Teletubbies also works as a site for exposing some of those arguments' hesitations, ambiguities and problems. The issue I have dwelt on most has been the precise forms that the concept of childhood takes in Teletubbies and in some postmodernist thinking, and although there are interesting correspondences between them, I have shown that childhood is far from precise in either the programme or the theory. Each of them works on an absent childhood and absent children that are at the centre of their discourse and also frame its borders. Forming a conception of childhood and adducing knowledge about actual children is an inescapable task for Teletubbies and, it seems, for postmodernist thinking that bases its sense of the present on a retrospectively constructed past. But at the same time as childhood and children become familiar and knowable others, they introduce into adulthood and the lives of adults the alienness and unknowability that they represent. Considering Teletubbies in this way is an excellent means to deconstruct what is at stake in television for children, and what children and childhood are for television. 


\section{ENDNOTES}

${ }^{1}$ This article draws on a broader theoretical argument about postmodernism and children's media in Jonathan Bignell, Postmodern Media Culture (Edinburgh: Edinburgh University Press, 2000), 114-38.

${ }^{2}$ David Buckingham, 'Child-centred television?: Teletubbies and the educational imperative', in D. Buckingham (ed.), Small Screens: Television for Children (Leicester: Leicester University Press, 2002), pp.38-61.

${ }^{3}$ Jean-François Lyotard, 'Answering the question: what is postmodernism?' in Thomas Docherty (ed.), Postmodernism: A Reader (Hemel Hempstead: Harvester Wheatsheaf, 1993), p.44.

${ }^{4}$ The South Warwickshire Director of Tourism, Alex Holmes, reported: 'This summer, our visitor information patrols have been asked more about where to find the Teletubbies than about the birthplace of William Shakespeare' (M. Bergman, 'The New Fab Four', Radio Times 27th September-3rd October 1997, p.20).

${ }^{5}$ See Rick Altman, 'Television sound', in Horace Newcombe (ed.), Television: The Critical View (London and New York: Routledge, 1987), pp.566-85. Karen Lury discusses television sound using Teletubbies as a case study in K. Lury, Interpreting Television (London: Hodder Arnold, 2005), pp.57-94.

${ }^{6}$ On the history of children's television's pseudo-parental functions, see David Oswell, 'Watching with mother in the early 1950s', in Cary Bazalgette and David Buckingham (eds), In Front of the Children: Screen Entertainment and Young Audiences (London: BFI, 1995), pp.34-46. 
${ }^{7}$ A sequence showing empirical research through play at Ragdoll's headquarters appears in the documentary Big Hug: The Making of Teletubbies (BBC 1998).

${ }^{8}$ Davenport discusses his original conception of the Teletubbies in Big Hug, which also shows some of his original artwork based on miniature astronauts in a garden.

${ }^{9}$ For example, the film Earth Girls Are Easy (Julien Temple, 1988) makes comic play with furry coloured aliens whose knowledge of Earth is based on watching US television. ${ }^{10}$ Jean-François Lyotard, The Inhuman, trans. G. Bennington (Cambridge: Polity, 1991). Dan Fleming, Powerplay: Toys as Popular Culture (Manchester: Manchester University Press, 1996), p.194.

${ }^{11}$ Neil Postman, The Disappearance of Childhood (London: W. H. Allen, 1983).

${ }^{12}$ I have analysed this duality in relation to toys in Jonathan Bignell, 'Where is Action Man's penis?: determinations of gender and the bodies of toys', in Naomi Segal, Lib Taylor and Roger Cook (eds), Indeterminate Bodies (Basingstoke: Palgrave Macmillan, 2003), pp.36-47, Jonathan Bignell, “"Get ready for action!”: reading Action Man toys', in Dudley Jones and Tony Watkins (eds), 'A Necessary Fantasy?': The Heroic Figure in Children's Popular Culture (New York \& London: Garland, 2000), pp.231-50, and Jonathan Bignell, 'The meanings of war toys and war games', in Ian Stewart and Susan Carruthers (eds), War, Culture and the Media: Representations of the Military in $20^{\text {th }}$ Century Britain (Trowbridge: Flicks, 1996), pp.165-84.

13 This argument about materiality and identity is used in deconstructive work on the body in relation to sexual identity, in Judith Butler, Bodies That Matter: On the Discursive Limits of Sex (London and New York: Routledge, 1993).

${ }^{14}$ Roger Singleton-Turner, Television and Children (London: BBC, 1994). 
${ }^{15}$ Singleton-Turner, Television and Children, p.23.

${ }^{16}$ Ibid.

17 ‘About Teletubbies', accessed from www.ragdoll.co.uk.

${ }^{18}$ On initial responses to Teletubbies from parents, educators and the press, see David Buckingham, 'Telly trouble', English and Media Magazine no.39 (Autumn 1998), pp.1418.

${ }^{19}$ Celia Dodd, 'Teletubbies mastermind', Radio Times 27th September-3rd October 1997, p.22.

${ }^{20}$ See Jonathan Bignell, 'Writing the child in media theory', Yearbook of English Studies no.32 (2002), pp.127-39.

${ }^{21}$ Jason Jacobs, 'Teletubbies', in Glen Creeber (ed.), Fifty Key Television Programmes (London: Arnold, 2004), pp.203-7; Lury, Interpreting Television, pp.88-94. 